\title{
ESTRATÉGIAS DE SOBREVIVÊNCIA E AVANÇO NUMA ORGANIZAÇÃO DO TERCEIRO SETOR: O PAPEL DOS CAPACITADORES DO CONHECIMENTO NA JUNIOR ACHIEVEMENT DE MINAS GERAIS
}

\section{RESUMO}

Conhecimento e inovação sempre caminharam juntos. Alguns autores vinculam a gestão do conhecimento (GC) como fator estratégico determinante para o desenvolvimento das organizações, para o processo de inovação contínua e o consequente aumento da competitividade. Este artigo tem como objetivo investigar as contribuições dos capacitadores do conhecimento para a criação do conhecimento e as estratégias de sobrevivência e avanço numa empresa do terceiro setor, à luz do modelo de Von Krogh, Ichijo e Nonaka (2001). O estudo de caso descritivo foi realizado na Junior Achievement de Minas Gerais (Jamg) cuja missão é a difusão da educação empreendedora e que tem no conhecimento e na inovação seus principais produtos e ativos. Os resultados mostraram que os capacitadores do conhecimento analisados contribuem para a criação do conhecimento na Jamg e para suas estratégias de sobrevivência e avanço. O capacitador "criar o contexto adequado" revela ser o ponto mais forte da organização; a qualidade de seu ambiente interno, no qual os relacionamentos dos colaboradores aparentam ser "permeados pela solicitude e pelo humanismo". Também foram identificados vários pontos de melhoria.

Palavras-chave: Estratégia, Criação do Conhecimento; Capacitadores para o Conhecimento; Gestão do Conhecimento; Inovação.

\section{STRATEGIES FOR SURVIVAL AND ADVANCE IN A THIRD SECTOR ORGANIZATION: THE ROLE OF KNOWLEDGE ENABLERS IN THE JUNIOR ACHIEVEMENT OF MINAS GERAIS}

\begin{abstract}
Knowledge and innovation have always worked together. Some authors associate knowledge management (KM) as a strategic determinant factor for organization development and for the process of continuous innovation with its resulting increase in competitiveness. This article aims to investigate the contributions of the knowledge enablers for knowledge creation and the strategies of survival and advance in a third sector company, following the model of Von Krogh, Ichijo and Nonaka (2001). The descriptive case study was conducted at Junior Achievement of Minas Gerais (Jamg), whose mission is the diffusion of entrepreneurial education and it has the knowledge and innovation as its main products and also its main assets. The results showed that the analyzed knowledge enablers contribute for the creation of knowledge in Jamg, and therefore for their survival and advancing strategies. The keystone "Creating a Proper Context" reveals what appears to be the strongest point of the organization: the quality of its indoor environment, in which the employees relationships appear to be "permeated by solicitude and humanism". Some points for improvement were also identified.
\end{abstract}

Keywords: Strategy; Knowledge Creation; Knowledge Enablers; Knowledge Management; Innovation. 


\section{ESTRATEGIAS DE SUPERVIVENCIA EN ADELANTADO Y ORGANIZACIÓN DEL TERCER SECTOR: EL PAPEL DE LOS ENTRENADORES DE CONOCIMIENTO EN EL LOGRO DE JUNIOR GENERAL MINAS}

\section{RESUMEN}

El conocimiento y la innovación siempre han ido de la mano. Algunos autores la gestión del conocimiento asociado (KM) como un factor determinante para el desarrollo de las organizaciones, el proceso de innovación continua y el factor estratégico de competitividad consecuente aumento. Este artículo tiene como objetivo investigar las aportaciones de los facilitadores del conocimiento a la creación de conocimientos y estrategias para la supervivencia y el progreso en una empresa del tercer sector a la luz de los Von Krogh, Ichijo y Nonaka modelo (2001). El estudio de caso descriptivo se realizó en Junior Achievement de Minas Gerais (JAMG), cuya misión es la difusión de la educación empresarial y que tiene el conocimiento y la innovación en sus productos básicos y bienes. Los resultados mostraron que los facilitadores del conocimiento analizadas contribuyen a la creación de conocimiento en JAMG y sus estrategias de supervivencia y el progreso. El entrenador de "crear el contexto adecuado" resulta ser el punto de la organización más fuerte; la calidad de su ambiente interior, en el que las relaciones de los críticos parecen estar "atravesada por la preocupación y el humanismo." También se identificaron varias áreas de mejora.

Palabras clave: Estrategia; Creación de Conocimiento; Facilitadores para el Conocimiento; Gestión del Conocimiento; Innovación.

\footnotetext{
${ }^{1}$ Mestre em Administração pelo Mestrado Profissional em Administração da Faculdade Pedro Leopoldo - FPL. Brasil. E-mail: crabraga@uol.com.br

${ }^{2}$ Doutora em Ciências da Informação pela Universidade Federal de Minas Gerais - UFMG. Professora da Faculdades Pedro Leopoldo - FPL. Brasil. E-mail: celestevasconcelos@gmail.com

${ }^{3}$ Doutor em Administração pela Universidade de São Paulo - USP. Diretor do Programa de Pós-Graduação em Administração da Univesidade Nove de Julho - PPGA/UNINOVE. Brasil. E-mail: maccari@uninove.br

${ }^{4}$ Doutor em Génie Industriel Et Gestion de L'innovation Techno pelo École Centrale de Paris, França. Professor da Faculdades Pedro Leopoldo - FPL. Brasil. E-mail: jtrneves@ gmail.com
} 


\section{INTRODUÇÃO}

O acirramento da concorrência no ambiente empresarial tem exigido, de maneira crescente, uma contínua renovação de conceitos, seja das formas de gestão, seja da maneira de obter os conhecimentos necessários ao sucesso dos negócios. Com o enfraquecimento dos modelos de gestão organizacionais adotados desde a Revolução Industrial e a ascensão da chamada "era do conhecimento", as organizações se aperceberam de que o conhecimento e não mais o acesso aos recursos naturais abundantes, mão de obra barata ou tecnologia - se transformou no fator determinante para o estabelecimento e a manutenção de vantagens competitivas que lhes garantam sobrevivência e expansão (Drucker, 1993).

O Brasil, considerado a sétima economia global (Portal G1, 2013), não se mantém à parte deste processo de urgência do aumento de competitividade, principalmente pela dependência do setor externo para a viabilização de sua economia.

O governo brasileiro, com o objetivo de reduzir o impacto dos fatores que ocasionam a baixa produtividade do país, vem tentando implementar um rol de políticas públicas que visam estimular a inovação e a competitividade, sobretudo de setores considerados estratégicos, pela sua dependência dos mercados externos ou pelo uso intensivo de mão de obra (Portal Brasil, 2013). Alguns setores da economia ressaltam que o Brasil tem um grande desafio pela frente e "10 anos é pouco" para o Brasil ter "[...]planejamento competitivo em todas as frentes" (Portal Uol, 2013)

Sabe-se que nenhum governo tem conseguido atender a todas as demandas surgidas em suas sociedades. Na esteira dessas demandas não atendidas, cidadãos oriundos da sociedade civil, e também dos setores público e privado, passaram a se organizar sob a égide do voluntariado, agregando seus múltiplos conhecimentos e criando o chamado terceiro setor. Essa parcela da sociedade vem ocupando espaços cada vez mais significativos e colaborando ativamente com os governos no encaminhamento e na solução de questões relevantes para a sociedade, além de promover o resgate e a inserção social de um número crescente de pessoas (Bndes, 2001).

$\mathrm{Na}$ busca pela almejada competitividade, observa-se que os temas "gestão do conhecimento", "criação do conhecimento" e "capacitadores do conhecimento" têm atraído considerável atenção e motivado a realização de diversos estudos, tais como os de Júnior (2013), Kuniyoshi et al. (2013), Sá et al. (2013), Santos \& Popadiuk (2010) e Silva (2013), embora ainda sejam escassas as pesquisas focadas no terceiro setor.

Desta forma, objetivando investigar as contribuições dos capacitadores do conhecimento para a criação do conhecimento e para as estratégias de sobrevivência e avanço numa organização do terceiro setor, foi realizado um estudo de caso na Junior Achievement de Minas Gerais (Jamg), cuja missão é a difusão da educação empreendedora e que tem no conhecimento e na inovação seus principais produtos e também seus principais ativos.

Este artigo está estruturado em cinco itens, sendo o primeiro representado por esta introdução, que vem contextualizar o tema e apresentar os objetivos e as justificativas. A revisão da bibliografia quanto à gestão do conhecimento, capacitadores do conhecimento e sua contribuição para a criação do conhecimento é tratada no segundo item. O terceiro item descreve os procedimentos metodológicos utilizados. A discussão dos resultados da pesquisa é apresentada no quarto item. O quinto item trata das conclusões e recomendações.

\section{GESTÃo E CAPACITAÇÃO PARA O CONHECIMENTO}

O conhecimento sempre esteve presente na vida da humanidade. Das eras primitivas à era contemporânea ele permeou todo o processo evolutivo da espécie e foi o fator decisivo para o sucesso daqueles que o possuíam, fossem pessoas, organizações ou nações. Stewart (1998, p. 5) faz da vitória dos guerreiros primitivos, que aprenderam a fundir o ferro e assim derrotaram os adversários que ainda utilizavam armas de bronze, um exemplo, acrescentando que "[...]não é à toa que somos chamados homo sapiens, o homem que pensa".

No entanto, foi na esteira da passagem da economia baseada na industrialização para a economia da informação e, posteriormente, para a economia do conhecimento, que este fator - o conhecimento ganhou visibilidade e atraiu a atenção das organizações. Na verdade, a partir do impacto das mudanças contínuas, do acirramento da competição por mercados e pela necessidade premente de estabelecer ganhos de produtividade e diferenciais competitivos, que as organizações e os indivíduos se deram conta de que o fator de diferenciação havia migrado daqueles reconhecidamente tradicionais - capital, terra e trabalho - para o conhecimento, este valor existente no cerne dos indivíduos, dos grupos e também das organizações (Drucker, 1993; Nonaka \& Takeuchi, 1997).

Nas palavras de Drucker (1993, p.16), o conhecimento é o novo e fundamental recurso econômico para a criação de riquezas e para o sucesso das organizações, sendo que a geração de valor deriva diretamente da aplicação do conhecimento no trabalho (o fazer), por meio da inovação e do aumento da produtividade. Stewart (2002, p.35) corrobora a posição de Drucker (1993) ao afirmar que 
"conhecimento é o que fazemos". O autor também vislumbra esta transformação do conhecimento no fator econômico mais importante para os indivíduos, as organizações e nações. Em sua dimensão imaterial, o conhecimento possui mais relevância do que os produtos (materiais) gerados pela Era Industrial. No mesmo sentido, Davenport e Prusak (2003, p.20) ressaltam a sustentabilidade do conhecimento:

[...] A vantagem do conhecimento é sustentável porque gera retornos crescentes e dianteiras continuadas. Ao contrário dos ativos materiais, que diminuem à medida que são usados, os ativos do conhecimento aumentam com o uso.

No bojo da elaboração de seu modelo de criação de conhecimento organizacional, Nonaka \& Takeuchi (1997, p.63) se debruçam por sobre um grande referencial, que inclui filosofia oriental e ocidental. Os autores adotam os conceitos de Michael Polanyi (1966) para classificar o conhecimento em tácito e em explícito: O conhecimento tácito é um conjunto de saberes pessoais, desenvolvidos por meio das experiências, percepções, valores e modelos mentais, difíceis de serem externados, compartilhados e transmitidos. São eminentemente subjetivos. Na visão dos teóricos japoneses, este é o conhecimento mais precioso (Nonaka \& Takeuchi, 1997). Já o conhecimento explícito, por outro lado, é objetivo, externado seja por meio de palavras ou de registros formais, tais como documentos, relatórios, livros, registros numéricos e procedimentos organizacionais, o que lhe confere o caráter de ser facilmente difundido entre indivíduos, diretamente ou com o auxílio da tecnologia. Este, o conhecimento explícito é o que atrai as atenções e o foco dos gerentes e teóricos ocidentais (Nonaka \& Takeuchi, 1997, p.7).

No entanto, na formulação de seu modelo dinâmico de criação do conhecimento, Nonaka \& Takeuchi (1997), ao contrário de outras correntes teóricas que buscam definir qual das duas instâncias é a mais relevante, consideram que ambas as dimensões são importantes e complementares. É por meio da interação destas duas dimensões - a tácita e a explícita - processo nomeado como "conversão do conhecimento", que ocorre a criação do conhecimento, primeiramente no nível do indivíduo e, posteriormente, caso existam condições organizacionais propícias, pelo compartilhamento para o grupo e para a organização, havendo, então a criação do conhecimento organizacional. É por meio das contribuições destes autores que um novo entendimento acerca do conhecimento organizacional será formado: o que afirma ser a criação do conhecimento uma tarefa estratégica das organizações e considerada a única capaz de fomentar um processo de inovação contínua que lhes garanta a dianteira competitiva.
Conforme pregam Nonaka e Takeuchi (1997) cabe às empresas criar o ambiente organizacional adequado à promoção do conhecimento, o chamado ba ou contexto capacitante. A criação desta ambiência favorável à troca, ampliação e disseminação do conhecimento e do aprendizado é também citada por Von Krogh, Ichijo e Nonaka (2001) e por Choo (2003).

Von Krogh et al. ressaltam que a criação do contexto capacitante é "[...] condição fundamental para que o processo aconteça e o conhecimento seja gerado" (2001, p.16). Assim sendo, o foco no conhecimento é preponderante para as organizações que desejam estar na vanguarda competitiva ou conquistá-la. Tendo como base a observação de como se deu a evolução das práticas da gestão do conhecimento nas organizações, os autores identificaram diversas barreiras que dificultam ou impedem a criação do conhecimento. Apresentaram, então, as questões que merecem atenção e ajuste e, para superá-las, propuseram a utilização de seu modelo de "capacitação para o conhecimento". De início, registraram que, em grande número de empresas, a prática da chamada "gestão do conhecimento" resumia-se ao uso intensivo de sistemas e tecnologias de informação e do estabelecimento de controles e métricas que, em vez de estimularem o processo de criação do conhecimento, o bloqueavam. Desta forma, perceberam um claro deslocamento de foco: da criação do conhecimento para o seu gerenciamento. Reconheceram, também, como importante barreira a ser eliminada, que os "assuntos do conhecimento", geralmente, ficam confinados à responsabilidade de áreas específicas, tais como Pesquisa e Desenvolvimento (P\&D), recursos humanos ou de tecnologia da informação, dissociando da alta gestão e do corpo operacional das empresas a noção de que a geração de conhecimento novo e de forma contínua é determinante para o sucesso organizacional e que deve envolver a todos para o seu atingimento. Em outras palavras, a necessidade da criação do conhecimento como fator estratégico para a organização não fica expressa no planejamento e na estratégia organizacional, nem tampouco compõe o plano de ações das mesmas.

Partindo destas constatações, os autores ressaltam: "Estamos absolutamente convencidos de que não se gerencia o conhecimento, apenas capacita-se para o conhecimento" (Von Krogh et al., 2001, prefácio). Os autores propõem, portanto, a criação de um modelo, não de gestão, mas de "capacitação para o conhecimento", que é uma evolução dos modelos desenvolvidos anteriormente, tais como os de Nonaka e Takeuchi (1997) e Probst, Raub e Romhardt (2002), e que tem como pilares:

- A inclusão, no referencial estratégico da organização, de que a criação do conhecimento organizacional é condição fundamental para sua sobrevivência e seu 
crescimento, de forma a traduzir com clareza sua importância para todas as instâncias da organização;

- O alinhamento deste referencial estratégico aos planos de ação organizacionais, permitindo ações coordenadas para a promoção deste objetivo; e

- A transformação do papel dos gerentes em protagonistas fundamentais para a promoção de todas as circunstâncias facilitadoras visando à criação e difusão do conhecimento na organização.

Outro ponto relevante do modelo é a identificação feita por Von Krogh et al. (2001, p.1819), de que a necessidade de justificativa, explicação, persuasão e coesão humana - que caracteriza o processo de interação entre o indivíduo e o grupo para a criação do conhecimento - faz deste processo algo extremamente frágil. Assim sendo, propõem a utilização de instrumentos de apoio que venham proporcionar sustentação ao processo, elevando suas chances de sucesso. A este apoio chamam de "capacitadores para o conhecimento".

\subsection{Os capacitadores para o conhecimento e as fases da criação do conhecimento,}

São cinco os chamados capacitadores para o conhecimento. A figura 1 mostra os capacitadores e suas respectivas contribuições para as fases da criação do conhecimento.

\begin{tabular}{|c|c|c|c|c|c|c|}
\hline & $\begin{array}{l}\text { Capacitadores do } \\
\text { conhecimento }\end{array}$ & $\begin{array}{l}\text { Compartilhamento do } \\
\text { conhecimento tácito }\end{array}$ & $\begin{array}{l}\text { Criação de } \\
\text { conceitos }\end{array}$ & $\begin{array}{l}\text { Justificação de } \\
\text { conceitos }\end{array}$ & $\begin{array}{l}\text { Construção de } \\
\text { protótipos }\end{array}$ & $\begin{array}{l}\text { Nivelação do } \\
\text { conhecimento }\end{array}$ \\
\hline 1) & Instilar a visão & - & $\mathrm{X}$ & $\mathrm{XX}$ & $\mathrm{X}$ & $\mathrm{XX}$ \\
\hline 2) & $\begin{array}{l}\text { Gerenciar as } \\
\text { conversas }\end{array}$ & $\mathrm{XX}$ & $\mathrm{XX}$ & $\mathrm{XX}$ & $\mathrm{XX}$ & $\mathrm{XX}$ \\
\hline 3) & Mobilizar os ativistas & - & $\mathrm{X}$ & $\mathrm{X}$ & $\mathrm{X}$ & $\mathrm{XX}$ \\
\hline & $\begin{array}{l}\text { Criar o contexto } \\
\text { adequado }\end{array}$ & $X$ & $X$ & $\mathrm{XX}$ & $\mathrm{X}$ & $\mathrm{XX}$ \\
\hline & $\begin{array}{l}\text { Globalizar o } \\
\text { conhecimento local }\end{array}$ & - & - & - & - & $\mathrm{XX}$ \\
\hline
\end{tabular}

Figura 1 - Capacitadores para o conhecimento e as fases da criação do conhecimento Legenda: X significa intensidade, XX significa maior intensidade.

Fonte: Von Krogh et al. (2001, p.18)

Os capacitadores da figura 1 são caracterizados da seguinte forma:

- "Instilar a visão do conhecimento": representada pela capacidade da organização de difundir adequadamente, e por todos os níveis, a ideia de quão fundamental é para o sucesso dos negócios o processo de criação do conhecimento;

- "Mobilizar os ativistas do conhecimento": diz respeito a conclamar à ação as lideranças, aquelas pessoas que irão formar, coordenar e estimular as equipes multidisciplinares envolvidas nas várias fases do processo de criação do conhecimento;

- "Criar o contexto capacitante", ou o ba, considerado pelos autores como o elementochave para que as outras fases da criação do conhecimento possam ocorrer. Nesse sentido, enfatiza-se a necessidade de se estimular a solicitude, a humanização da equipe, como forma de criar o primeiro ambiente capacitante adequado $-\mathrm{o}$ indivíduo predisposto ao processo. Esta atitude de solicitude deve permear as relações e proporcionar uma maior e melhor interação entre os elementos das microcomunidades, definidas como agrupamentos constituídos por elementos humanos com diversas formações e especificidades, vindos de localidades diferentes ou não (local ou global), que se somam para a consecução de um projeto comum. Para os autores "[...]a principal qualidade dos trabalhadores do conhecimento é o humanismo" (2001, p.22);

- "Globalizar o conhecimento local": diz respeito à difusão, por todos os níveis da organização, dos conhecimentos gerados por grupos específicos, ou microcomunidades. Os autores ressaltam a importância deste capacitador quando a criação e a utilização do conhecimento estão dissociadas no tempo e no espaço, havendo então a necessidade de difundi-lo para que novos conhecimentos possam vir a ser gerados; 
- O capacitador "gerenciar as conversas" foi deixado por último por ter sido considerado pelos autores Von Krogh et al. (2001), como o mais impactante de todos, conforme pode ser percebido na figura 1 , uma vez que exerce forte influência sobre as cinco fases da criação do conhecimento, por estar ligado às pessoas, aos relacionamentos e à solicitude apregoada pelo modelo.

Nesta pesquisa, optou-se por utilizar o modelo de Von Krogh et al. (2001), devido à sua proposta de "capacitação para o conhecimento" para a criação do conhecimento das organizações e para as estratégias de sobrevivência e avanço.

A figura 2 apresenta a ligação do conhecimento com a vantagem competitiva e as estratégias de sobrevivência e o avanço da organização. Observa-se que são ressaltados os vários processos de conhecimento da organização, incluindo a criação e transferência do conhecimento e a inovação.

\begin{tabular}{|c|c|c|c|c|c|}
\hline 兘 & $\begin{array}{l}\text { VANTAGEM } \\
\text { COMPETITIVA }\end{array}$ & $\begin{array}{c}\text { FONTES DA } \\
\text { VANTAGEM } \\
\text { COMPETITIVA }\end{array}$ & $\begin{array}{c}\text { PAPEL DO } \\
\text { CONHECIMENTO }\end{array}$ & $\begin{array}{c}\text { IMPORTANTES } \\
\text { PROCESSOS DE } \\
\text { CONHECIMENTO }\end{array}$ & 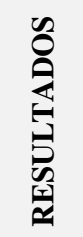 \\
\hline \multirow{3}{*}{ 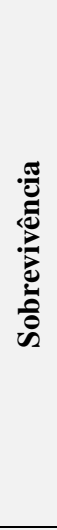 } & $\begin{array}{l}\text { Rentabilidade } \\
\text { corrente }\end{array}$ & Economias de escala & $\begin{array}{l}\text { Valioso, difícil de } \\
\text { imitar e de substituir }\end{array}$ & $\begin{array}{c}\text { Transferência de } \\
\text { conhecimento }\end{array}$ & . \\
\hline & $\begin{array}{c}\text { Não } \\
\text { implementada } \\
\text { pelos } \\
\text { concorrentes }\end{array}$ & Economias de escopo & Exclusivo ou público & \multirow{2}{*}{ Melhoria contínua } & 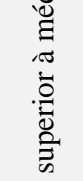 \\
\hline & $\begin{array}{l}\text { Os que tentam } \\
\text { não conseguem } \\
\text { reproduzir as } \\
\text { vantagens } \\
\text { originais } \\
\end{array}$ & $\begin{array}{l}\text { Diferenciação de } \\
\text { produtos e serviços }\end{array}$ & $\begin{array}{c}\text { Capacidade de } \\
\text { transferência, às } \\
\text { vezes, é mais } \\
\text { importante que o } \\
\text { conteúdo }\end{array}$ & & 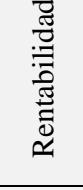 \\
\hline \multirow{3}{*}{ 总 } & $\begin{array}{l}\text { Rentabilidade } \\
\text { futura }\end{array}$ & $\begin{array}{c}\text { Economia de escala } \\
\text { potenciais }\end{array}$ & $\begin{array}{l}\text { Novos conhecimentos } \\
\text { para inovação dos } \\
\text { processos e produtos }\end{array}$ & Criação de conhecimento & $\stackrel{\pi}{\frac{\pi}{2}}$ \\
\hline & $\begin{array}{c}\text { Não } \\
\text { implementada } \\
\text { pelos } \\
\text { concorrentes } \\
\end{array}$ & $\begin{array}{c}\text { Economias de escopo } \\
\text { potenciais }\end{array}$ & \multirow{2}{*}{$\begin{array}{l}\text { Novos conhecimentos } \\
\text { transferíveis }\end{array}$} & \multirow[b]{2}{*}{ Inovação radical } & 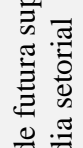 \\
\hline & $\begin{array}{l}\text { Os que tentam, } \\
\text { não conseguem } \\
\text { reproduzir as } \\
\text { vantagens } \\
\text { originais }\end{array}$ & $\begin{array}{c}\text { Diferenciação } \\
\text { potencial de produtos } \\
\text { e serviços }\end{array}$ & & & 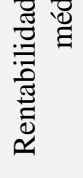 \\
\hline
\end{tabular}

Figura 2 - Referencial estratégico para o conhecimento

Fonte: Von Krogh, Ichijo e Nonaka (2001, p. 93)

O papel estratégico do conhecimento e seus processos são ressaltados nas colunas quatro e cinco do Quadro 2, a vantagem competitiva e suas fontes são mostradas nas colunas dois e três, as estratégias de sobrevivência e avanço na coluna hum e os resultados a serem alcançados na coluna seis. Ressalta-se que, para a organização sobreviver, tem de manter seu foco na transferencia do conhecimento e melhoria contínua. Já para avançar, tem de manter seu foco também na criação do conhecimento e na inovação.

O próximo item apresenta a metodologia utilizada na pesquisa. 


\section{METODOLOGIA}

A pesquisa foi classificada como um estudo de caso descritivo. De acordo com Gil (2002), pesquisa descritiva é a que deseja identificar atitudes ou opiniões manifestas em uma população. Já segundo Collis \& Hussey (2005, p.24), ela possui como foco descrever o comportamento dos fenômenos e é o que se espera conseguir dentro da organização pesquisada. Yin (2001) define estudo de caso como sendo uma estratégia de pesquisa na qual estão adequadamente explicitados o planejamento, a coleta de dados e sua análise dos mesmos.

Quanto ao método, a pesquisa pode ser classificada como qualitativa, que, ao contrário da quantitativa, é mais subjetiva e se propõe a "examinar e refletir as percepções para obter um entendimento de atividades sociais e humanas". A ênfase da pesquisa qualitativa é na qualidade e na profundidade dos dados, que serão plenos de significados (Collis \& Hussey, 2005, p.26).

A unidade de análise escolhida foi a Junior Achievement de Minas Gerais (JAMG), organização do terceiro setor com foco na difusão do empreendedorismo para um público constituído de alunos que vão desde os anos básicos de ensino fundamental até aqueles cursando o segundo ano do ensino médio. A Junior Achievement é a maior e a mais antiga organização voltada para a educação empreendedora existente no mundo. Fundada nos Estados Unidos em 1919, está presente em mais de 120 países e, no Brasil, em todos os estados e no Distrito Federal, sendo que cerca de 2,6 milhões de alunos já foram beneficiados com seus diversos programas, que contaram com o envolvimento e empenho de mais de 100 mil voluntários (JABR, 2013).

Em Minas Gerais, a JAMG atua desde 2003, operando 20 programas, que têm como meta capacitar 17.000 jovens em 2013, envolvendo 1.000 voluntários em 150 escolas. Caracteriza-se por ser uma associação educativa sem fins lucrativos, mantida pela iniciativa privada e que exerce suas atividades por meio de voluntários que se disponibilizam para os diversos programas da organização. Seu principal objetivo é despertar o jovem para o mundo dos negócios, capacitando-o, por meio do conhecimento básico acerca da economia e da vivência empreendedora, a buscar melhores condições de vida e progresso para si mesmo e para a coletividade que o cerca. Dando sustentação financeira às suas atividades, a JAMG conta com 41 empresas mantenedoras, bem como diversas outras como parceiras e associadas para provêla de soluções e multiplicar sua ação (JAMG, 2013).

A unidade de observação da pesquisa foi composta por sete colaboradores da organização, assim caracterizados: sua Gerente Geral, dois gestores de projetos, dois assistentes de gestão de projetos, o responsável pela comunicação e marketing e a responsável pela logística. A pesquisa foi realizada por meio por meio de entrevistas pessoais (vide apresentação e discussão dos resultados), com prazo de duração média de 40 minutos cada uma, na sede da organização pesquisada e com um contingente de sete pessoas, escolhidas pelo critério da acessibilidade e por se constituírem pela totalidade do staff da organização com informações relevantes para sua elaboração. É importante ressaltar que, de acordo com recomendações de Collis \& Hussey (2005, p.162), as entrevistas foram gravadas.

Como estratégia de análise, os dados obtidos foram tratados por meio da análise de conteúdo, que, de acordo com Collis \& Hussey (2005, p.240), é um método formal para a análise de dados qualitativos. Mostyn (1985), citado por Collis \& Hussey (2005, p. 240), acrescenta que "a análise de conteúdo é uma ferramenta de diagnóstico de pesquisadores qualitativos, que a empregam quando se veem diante de uma massa de material que deve fazer sentido".

\section{APRESENTAÇÃO E DISCUSSÃO DOS RESULTADOS}

Neste item são apresentados os resultados obtidos nas entrevistas, de forma a demonstrar o atingimento dos objetivos estabelecidos, bem como sua discussão à luz do referencial teórico. São analisados a seguir os cinco capacitadores e sua contribuição para a criação do conhecimento.

\subsection{Instilar a visão}

As perguntas do roteiro de entrevistas visaram introduzir o tema do conhecimento e criar um contexto adequado para os entrevistados entenderem melhor os objetivos da pesquisa, cujo tema foi apresentado previamente ao grupo, tendo sido explicados, em linhas gerais, os conceitos envolvidos. Observou-se que a maioria dos entrevistados possui uma noção muito clara acerca da importância do conhecimento como recurso a ser adquirido, para si mesmo, para o grupo e para a organização, e reconhece que a JAMG dá a ele uma grande importância.

$\mathrm{Na}$ pergunta 1, "Quais são as maneiras utilizadas pela JAMG para despertar a noção da importância do conhecimento?", os respondentes foram unânimes em reconhecer, primeiramente, que a organização consegue transmitir para a equipe a noção da importância do conhecimento. Isto é percebido de diversas formas, entre elas:

- Pelo estímulo dado aos seus colaboradores para que se aperfeiçoem continuamente, por meio da participação em cursos, palestras e eventos, bem como por meio de livros e publicações, cujos conteúdos são 
compartilhados entre a equipe e incorporados aos produtos e serviços oferecidos pela organização, fortalecendo o compartilhamento do conhecimento tácito;

- Flexibilidade de horário oferecida aos colaboradores, de forma a permitir seu engajamento nos programas da organização (como voluntários), o que permite que conheçam cada um dos programas como participantes e, ao vivenciá-los, possam sugerir e promover melhorias de seu escopo;

- Forte incentivo para o desenvolvimento de novas formas de treinamento para os voluntários e apresentações para a sensibilização de escolas e alunos, o que leva os colaboradores a buscarem sempre a utilização de novos softwares, dinâmicas e abordagens para os públicos envolvidos;

- Grande abertura para propostas de alterações ou ajustes dos materiais utilizados nos diversos programas, adaptando-os à realidade e até às exigências da legislação brasileira.

Embora concordem quanto à importância dada ao conhecimento pela JAMG, os colaboradores demonstram percepções bem diferentes quanto à forma como esta noção de importância é transmitida à equipe: alguns respondentes percebem que isto se dá formalmente, enquanto a maioria aponta que isto ocorre informalmente, sem que esteja registrado em qualquer documento ou externado desta forma à equipe. Algumas falas, transcritas abaixo, exemplificam esta percepção. formalidade:

Exemplo de percepção sobre a existência da

Nas reuniões da equipe de gestão dos projetos, que são rotina, sempre acontece a troca de experiências para se encontrar soluções para os problemas. Também acontece nas reuniões mensais de avaliação de desempenho, com toda a equipe, onde todos são estimulados a contribuir para a solução dos problemas, independente de sua área na organização ou sua função. Outro exemplo são os treinamentos de formação de voluntários. (responsável pela logística).

Exemplo de percepção diferente, que não identifica a formalidade:

Percebo que o conhecimento é valorizado na organização, mas informalmente: não é explicitada a sua importância, formalmente dizendo, mas como se lida com ele a todo momento, por meio dos manuais, elaboração de palestras para sensibilizar os alunos, treinar voluntários, etc. a noção de sua importância é automática. (responsável pela comunicação e marketing).
Para a Gerente Geral, existem sim, momentos em que a importância dada à criação de conhecimento novo e sua difusão pelo grupo é explicitada e formalizada, citando pelo menos duas ocasiões quando isso acontece:

- A reunião da equipe gestora dos projetos, quando são apresentados problemas comuns à aplicação dos programas (que atualmente são vinte), treinamento dos voluntários, interação com as escolas, com os alunos, com os voluntários e com as empresas mantenedoras, repasse da metodologia e avaliação posterior à aplicação dos programas;

- A reunião mensal de avaliação, com toda a equipe, que é chamada a participar e estimulada a buscar soluções para os problemas existentes, metas não atingidas e não conformidades identificadas; representa um momento importante de nivelamento do conhecimento.

Ainda no entendimento da Gerente Geral, nestes momentos é evidente a importância dada ao conhecimento pela organização, ocorrendo criação de conhecimento novo, seu compartilhamento e o seu registro formal, uma vez que todas as soluções encontradas e decisões tomadas ficam registradas em ata. A Gerente ressalta a existência do documento Histórico dos Projetos, no qual são registradas todas as alterações, melhorias e adaptações realizadas pelos colaboradores nos mesmos, constituindo-se em um registro pormenorizado da história de cada projeto, o que representa um forte estímulo a que todos participem de sua atualização, por meio da criação de conhecimento novo.

Para além das discordâncias sobre a forma de demonstração da importância dada ao conhecimento, há um ponto comum, presente em todas as entrevistas e considerado pelos respondentes como sendo a principal demonstração por parte da Gerente Geral da JAMG da importância dada ao conhecimento: o ambiente da organização. Os colaboradores reconhecem o empenho por parte da direção para a criação e manutenção de uma atmosfera de respeito, de acolhimento, de confiança mútua, entrosamento e de estímulo à participação de todos, para que sejam compartilhados os saberes e experiências, criando um forte comprometimento com a causa, com os desafios e resultados da organização.

Outro fator considerado pelos respondentes como extremamente importante para a criação deste clima organizacional tão favorável é a própria distribuição física do espaço da JAMG: todos trabalham no mesmo ambiente, próximos uns aos outros, o que favorece a interação em tempo integral e cria possibilidades a todo o tempo para que os 
conhecimentos sejam partilhados, construídos e nivelados. Abaixo, exemplos de falas sobre esta percepção:

O fato de trabalharmos todos juntos no mesmo lugar, próximos uns dos outros, facilita a interação e a troca de conhecimentos, sendo que os problemas e questões do dia a dia são divididos entre todos e todos participam da sua solução e também colaboram para a melhoria dos programas, por meio de sugestões. (responsável pela logística).

Como o ambiente de trabalho é formado por uma sala grande onde todos trabalham juntos, esta proximidade favorece a troca de informações, de busca de ajuda para a solução de problemas comuns, gerando resultados que são incorporados por todos em seu trabalho, mas informalmente. (responsável pela comunicação e marketing).

Dessa forma, pode-se identificar na organização pesquisada o atendimento a alguns dos preceitos do modelo proposto por Von Krogh et al. (2001), quais sejam:

- A inexistência da barreira à criação do conhecimento, representada - na maioria das organizações - pelo distanciamento da responsabilidade pela criação do conhecimento da equipe gerencial e operacional. Na Jamg, observa-se que este assunto não está confinado à responsabilidade de nenhuma área específica, mas permeia a equipe, que se sente estimulada e comprometida em promover melhorias contínuas nos programas que tem por missão repassar, levando-a a buscar o conhecimento externa e internamente, para o benefício da própria organização;

- Esta proatividade verificada nos colaboradores os caracteriza como os "protagonistas fundamentais para a promoção de todas as circunstâncias facilitadoras visando à criação e difusão do conhecimento na organização", conforme preceituam Von Krogh et al. (2001).

Quanto ao primeiro capacitador para o conhecimento - "Instilar a Visão do Conhecimento" objeto desta primeira pergunta da entrevista, pode-se afirmar que é utilizado parcialmente na JAMG. Essa parcialidade fica demonstrada nas entrevistas por meio das percepções divergentes dos respondentes quanto à sinalização da organização sobre a importância estratégica da criação do conhecimento para a mesma. Este item, portanto, constitui-se como um ponto de melhoria para que a JAMG torne explícita para a equipe a importância da criação do conhecimento, tanto para a sobrevivência quanto para o avanço da organização. Em acréscimo, é possível também afirmar que os resultados obtidos por meio dessa primeira pergunta atendem à primeira fase do modelo de conversão do conhecimento proposto por Nonaka \& Takeuchi (1997): o Compartilhamento do Conhecimento Tácito, claramente identificado nas respostas.

\subsection{Gerenciar as conversas}

A segunda pergunta. "Como os resultados das conversas e ideias dos colaboradores são utilizados em benefício da equipe e da JAMG?", obteve respostas divergentes entre os entrevistados, que se valeram de dois momentos distintos para a elaboração de suas respostas: a rotina do dia a dia de trabalho e as reuniões periódicas e formais já citadas.

O dia a dia dos trabalhos na organização foi considerado - pela totalidade dos entrevistados - como ponto forte para a criação e compartilhamento de informações e conhecimentos, uma vez que todos utilizam um mesmo ambiente (em estações de trabalho dispostas frente a frente ou lado a lado), a proximidade dos colaboradores permite e estimula a comunicação em tempo real, sendo um hábito a solicitação de ajuda entre os membros da equipe (independentemente de sua área de atuação ou função hierárquica) para a solução de questões e problemas apresentados, bem como para a implementação de melhorias nos diversos programas e projetos, comportamento este incentivado pela Gerente Geral. Algumas falas demonstram estas percepções:

Acho que as conversas são aproveitadas. Como o ambiente de trabalho é formado por uma sala onde todos trabalham juntos, essa proximidade favorece a troca de informações, de busca de ajuda para a solução de problemas comuns, gerando resultados que são incorporados por todos em seu trabalho, informalmente. (Responsável pela comunicação e marketing) (grifo do pesquisador).

As interações da equipe são ótimas e acontecem o tempo todo, o que ajuda na solução das questões apresentadas e também no processo de melhoria contínua dos projetos. (Gestor de projetos).

No entanto, se por um lado todos concordam que a interação ocorre em níveis satisfatórios, que ela é contínua e gera conhecimento e melhorias diversas para a organização, por outro lado, o mesmo não se dá em relação ao aproveitamento dos conhecimentos gerados. Isto é percebido nas respostas de alguns colaboradores, que afirmam não existir o hábito de registrar as soluções e melhorias produzidas por meio das conversas para uso posterior. Este fato comprometeria ou pelo menos limitaria a utilização dos conhecimentos gerados, ainda mais quando alertam 
que, em razão de diversas atividades externas, há sempre membros da equipe ausentes no ambiente do escritório, ficando esses à margem de se beneficiarem com os conhecimentos gerados em sua ausência. A fala abaixo registra esta preocupação:

Apesar de haver muita troca, em razão da proximidade física e também pela sensação de confiança e companheirismo da equipe, acho que os ganhos não são aproveitados como poderiam, porque não ficam registrados, principalmente para aqueles que não estão na hora, trazendo perdas para os ausentes, já que nem sempre estes ganhos são passados para eles. Na maioria das vezes nós vamos do problema direto para a solução. (Responsável pela logística).

Um segundo momento citado por alguns respondentes diz respeito às reuniões (formais e programadas) que acontecem periodicamente. Com respeito a elas, há concordância de que o resultado das conversas e da participação de todos é aproveitado, uma vez que, por serem reuniões formais, ficam devidamente registrados, por meio de atas, relatórios e abertura de planos de ação para a solução de problemas. A fala, abaixo, indica este posicionamento:

Nas reuniões de avaliação de desempenho ou com a equipe de gestão de projetos todos são estimulados a contribuir para a solução dos problemas enfrentados. Todos são chamados a participar e muitas soluções e propostas de melhoria são apresentadas e incorporadas aos trabalhos a partir daí. Por serem reuniões formais, fazemos atas e relatórios, alguns para uso interno da JAMG, outros que são encaminhados para as empresas mantenedoras ou para a JA Brasil. (Gerente Geral).

Assim sendo, as respostas obtidas com esta segunda pergunta da entrevista permitem afirmar que, por meio das conversas cotidianas desenvolvidas pela equipe, há geração de ideias e conhecimentos novos para seus membros e para a organização, reforçando os achados do modelo de Von Krogh et al. (2001), onde é clara a importância dada pelos autores ao "poder das conversas" (p.156) e, por consequência, para a tarefa de gerenciá-las em benefício de seus elementos e para as estratégias de sobrevivência e o avanço da organização. Nas palavras dos autores,

[...]o intercâmbio de ideias, opiniões e crenças, propiciado pelas conversas possibilita o primeiro e o mais importante passo da criação de conhecimento: o compartilhamento do conhecimento tácito dentro da microcomunidade. (Von Krogh et al., 2001, p.156).
Na JAMG, o estímulo à troca de conhecimentos - tanto por parte da Gerente Geral quanto da própria característica física do ambiente propicia exatamente as condições preconizadas por esses autores, podendo a organização até mesmo ser considerada como uma microcomunidade em tempo integral, uma vez que a soma de seus colaboradores perfaz um total de onze pessoas, que trabalham juntas em um mesmo ambiente, trocando seus conhecimentos e habilidades para o atingimento de níveis de excelência que atendam às expectativas dos seus mantenedores.

No entanto, as respostas sugerem que os resultados gerados dessa interação podem não estar sendo integralmente capturados em benefício do grupo e da organização, surgindo aí outra oportunidade de melhoria para a JAMG. Importante ressaltar que Von Krogh et al. (2001) consideram o capacitador "Gerenciar as Conversas" como o mais impactante de todos, uma vez que exerce forte influência sobre as cinco fases da criação do conhecimento, por estar ligado às pessoas, aos relacionamentos e à solicitude apregoada pelo modelo, solicitude esta facilmente identificada no trato entre os colaboradores da organização pesquisada.

\subsection{Mobilizar os ativistas}

Em resposta à terceira pergunta, "De que forma a JAMG identifica e estimula suas lideranças e ativistas para a criação e a difusão do conhecimento?", os respondentes apontaram diversas ocasiões em que essa identificação e estímulo ocorrem.

Primeiramente, focaram no incentivo à capacitação da equipe. Os entrevistados foram unânimes em afirmar o grande estímulo que recebem por parte da Gerente Geral para o seu autodesenvolvimento e capacitação, de forma que esta melhoria se reverta em benefícios para cada um, para o grupo e resulte na melhoria dos resultados da organização. Neste sentido, várias são as respostas que citam o incentivo para que participem de atividades fora da organização - desde que alinhadas aos propósitos da JAMG e úteis à função do colaborador -, tais como cursos, palestras e eventos, aos quais os entrevistados podem comparecer, inclusive, durante o horário de trabalho, em havendo necessidade. Este fato pode ser percebido por meio das falas:

O estímulo acontece informalmente, sem obedecer a uma programação ou rotina. Um exemplo é a indicação dos colaboradores para treinamentos de aperfeiçoamento em áreas do conhecimento que possam vir a agregar valor às tarefas executadas. Para isso, a Gerente Geral identifica os colaboradores afins e os estimula a fazer o treinamento, ao qual podem participar até mesmo dentro do horário de 
trabalho. (responsável pela comunicação e marketing).

Outro exemplo é a grande abertura para que os colaboradores experimentem novas funções e desenvolvam novas tarefas, inclusive fora de sua área de origem, estimulando sempre o compartilhamento de ideias, informações e conhecimentos. (responsável pela logística).

Num segundo momento ocorre o retorno dos colaboradores após a participação em atividades externas que proporcionem aprendizado. Isso diz respeito ao repasse e a difusão dos conhecimentos adquiridos, transformando-os de conhecimento individual tácito em conhecimento explícito, que, partilhado com a equipe, é transformado em conhecimento tácito do grupo, nesta primeira fase da criação do conhecimento.

São diversas as maneiras de esse processo ocorrer: treinamentos, cursos, reuniões, eventos e palestras. As respostas apontam como rotineiro o estímulo à partilha pela equipe, que se dá, na maioria das vezes, informalmente, exceção feita apenas quando o evento ocorre junto à JA Brasil ou a outra sede estadual da organização, havendo então um repasse para toda a equipe. Estas opiniões podem ser percebidas na fala abaixo:

Geralmente, no retorno dos eventos externos, os colaboradores são estimulados a compartilhar, com os que não foram, os conhecimentos observados, o que acontece por meio de conversas e por e-mails, onde replicam as informações, endereços eletrônicos com as informações, textos, etc. Recentemente, um dos gestores de projetos participou de um treinamento na JA Brasil e, no retorno, reuniu a equipe e replicou o conhecimento adquirido. (responsável pela logística).

Após situar o estímulo dado às lideranças para que se capacitem no sentido de criar e, posteriormente, difundir o conhecimento na organização, apresenta-se a maneira como a JAMG identifica e estimula suas lideranças e ativistas no dia a dia. Esta questão é tratada como estratégica pela Gerente Geral, conforme pode ser percebido em suas palavras:

Como a equipe é pequena, são onze colaboradores e são muitas as tarefas externas de interação junto à comunidade: escolas, empresas mantenedoras, captação e treinamento de voluntários, eventos em parceria, palestras de sensibilização, entre outros, há a preocupação de que todos conheçam muito bem a organização, seus princípios e valores. Assim, embora existam os líderes formais e estejam também identificados os líderes naturais, há todo um esforço em preparar toda a equipe para a tarefa de serem, onde estiverem, representantes plenos da JAMG. Desta forma, desenvolve-se, em todos, o conceito e a prática de liderança situacional, que tem funcionado muito bem.

De acordo com a Gerente Geral, no desempenho de sua missão, cada um dos membros da equipe da JAMG "assume grandes desafios", o que expressa sua liderança.

Ao apresentarem este terceiro capacitador para o conhecimento - "Mobilizar os Ativistas do Conhecimento" -, Von Krogh et al. (2001) ressaltam sua forte influência na última etapa de seu modelo para a criação do conhecimento: a de nivelamento do conhecimento, o que fortalece as estratégias para a sobrevivência e para o avanço da organização.

\subsection{Criar o contexto capacitante}

A pergunta de número quatro, "Quais são as estratégias utilizadas pela JAMG para criar um ambiente propício ao compartilhamento do conhecimento?", revela aquele que parece ser o ponto mais forte da organização: a qualidade de seu ambiente interno, no qual os relacionamentos dos colaboradores aparentam seguir as orientações de Von Krogh, Ichijo e Nonaka (2001, p.22) no sentido de que sejam "permeados pela solicitude e pelo humanismo".

A percepção e o reconhecimento de que se trabalha em um ambiente diferenciado ficam patentes na maioria das respostas, mas existem opiniões divergentes quanto a que este ambiente seja produto de estratégias deliberadas ou fruto do direcionamento da Gerente Geral ou, ainda, resultado da interação natural dos colaboradores. estratégias:

Exemplos de percepção da existência de

Acredito ser nas reuniões mensais de planejamento e acompanhamento que ocorrem os maiores estímulos para que todos os participantes se manifestem e contribuam para a solução de problemas ou para o atingimento de metas. Nestes encontros, todos são estimulados a se manifestar, amparados por um ambiente favorável à livre expressão e onde todos se sentem confortáveis em opinar. Há debates e participação intensa entre os membros da equipe. (gestor de projetos).

Acredito que a disposição da equipe toda no mesmo ambiente seja uma estratégia para que ocorra o compartilhamento do conhecimento gerado. Trabalhando todos juntos, a interação é natural e contínua. Mas, isto só é possível porque existe uma sinalização clara quanto ao respeito e a confiança entre a equipe: não há competição, ninguém está ameaçando a posição do outro e isto gera um clima muito bom, de companheirismo e liberdade para que 
as ideias sejam expostas. (responsável pela logística).

Como única estratégia formal percebida, vejo a reunião mensal de avaliação e planejamento, na qual toda a equipe é chamada a opinar e ser corresponsável pelos resultados gerados, em que todos são estimulados a participar, independentemente de sua área e especialização. (Assistente de gestão de projetos).

Exemplos de percepções diferentes, que não identificam a existência de estratégias:

\begin{abstract}
Desconheço qualquer estratégia para criar este ambiente que estimula a troca de conhecimentos: ele existe, é verdade, mas acredito que ele ocorre acidentalmente, sendo um procedimento natural da equipe, mas não como resultado de uma estratégia. (Assistente de gestão de projetos).

Existe o estímulo e o fomento para que sejam buscados novos conhecimentos e que eles sejam compartilhados entre a equipe. Percebo a ação e diversas formas de sinalização para a criação de um ambiente propício para que esta interação e troca aconteçam, mas não percebo a existência de estratégias formais que deem suporte a estas ações. (Gestor de projetos).
\end{abstract}

Portanto, em resposta a esta quarta pergunta, tem-se, primeiramente, o reconhecimento por parte de todos os respondentes de que trabalham em um ambiente extremamente propício a interação, à troca de conhecimentos e experiências e ao estímulo à criação de conhecimentos novos. De outra forma, percebem, também, o direcionamento e o empenho por parte da Gerente Geral da JAMG para a criação deste ambiente organizacional, também chamado de "contexto capacitante" ou ba pelos autores Nonaka e Takeuchi (1997), Choo (2003) e Von Krogh et al. (2001), sendo considerado como fator-chave para que as outras fases da criação do conhecimento possam ocorrer.

Uma vez que as respostas indicam a inexistência de um entendimento único por parte dos colaboradores da JAMG sobre as origens deste ambiente, ou seja, se ele é fruto de estratégias deliberadas ou apenas resultado da interação da equipe; acredita-se que esta também se constituiria em uma oportunidade de melhoria a ser avaliada pela Gerente Geral, que poderia explicitar claramente para toda a equipe como e de que forma este ambiente vem sendo construído.

\subsection{Globalizar o conhecimento local}

Nas respostas dadas à questão de número cinco, "Como o conhecimento que é gerado localmente é nivelado e difundido globalmente?", os respondentes demonstraram uma maior homogeneidade.

Em sua maioria, os respondentes concordam que, no nível interno da organização, de um modo geral, o nivelamento do conhecimento gerado é realizado, mas com deficiências. Como causas, reportam ruídos de comunicação, bem como a deficiência relatada na questão dois, qual seja: ausência de registro dos conhecimentos gerados na interação da equipe, para uso e proveito de todos os colaboradores. As falas transcritas a seguir representam uma amostra das respostas apresentadas:

Existem problemas de comunicação internos, o que dificulta o compartilhamento e o nivelamento do conhecimento entre os integrantes da equipe. Quanto à difusão externa, acho que não existe, sendo um ponto de melhoria inclusive já listado no plano de ações. (Assistente de gestão de projetos).

A Gerente Geral da JAMG está em permanente contato com as outras estaduais, realizando esta troca de boas práticas de forma sistemática. Uma ferramenta que vem sendo utilizada mais recentemente é o facebook, que liga a JAMG aos seus parceiros no estado. Pretende-se que esta ferramenta possa vir a ser utilizada também entre as estaduais, criando-se um canal mais informal para a troca de informações e boas práticas desenvolvidas em cada estadual. (Gestor de projetos).

Um exemplo de conhecimento desenvolvido aqui e enviado para a JA Brasil foi uma ferramenta financeira que foi desenvolvida pela JAMG em parceria com a Empresa Junior da UFMG, e que permite a orçamentação de cada projeto, quando da sua negociação com a empresa mantenedora e com as instituições beneficiárias. (Gestor de projetos).

Assim, percebe-se aqui, a interferência dos problemas apontados pelos respondentes para a questão de número dois (ausência de registro dos conhecimentos gerados a partir da interação da equipe), reforçando a sugestão para que os ajustes necessários à solução dos problemas apontados para esta questão sejam levados a efeito.

A "Globalização do conhecimento local”, que vem a ser o quinto capacitador para o conhecimento do modelo proposto por Von Krogh et al. (2001), aparenta ser o ponto que necessita de maior atenção por parte da JAMG para ser superado, ressaltando-se que este é um fato já conhecido pela equipe e incluído no plano de ações da organização. A falta de foco neste capacitador pode vir a comprometer a sobrevivência e o avanço da organização. 


\section{CONSIDERAÇÕES FINAIS}

Este artigo teve como objetivo investigar as contribuições dos capacitadores para o conhecimento para a criação do conhecimento e para as estratégias de sobrevivência e avanço da Junior Achievement de Minas Gerais (JAMG), organização do terceiro setor cuja missão é a difusão da educação empreendedora e que tem no conhecimento e na inovação seus principais produtos e também seus principais ativos. Para se atingir esse objetivo, foi realizado um estudo de caso descritivo, de natureza qualitativa. Foram feitas entrevistas individuais, na sede da organização, com duração média de quarenta minutos, com sete colaboradores da organização assim caracterizados: sua Gerente Geral, dois gestores de projetos, dois assistentes de gestão de projetos, o responsável pela comunicação e marketing e a responsável pela logística. Ressalta-se que sua escolha deveu-se aos critérios de acessibilidade e também pelo conhecimento que possuíam sobre a organização pesquisada.

Em relação às contribuições dos capacitadores para a criação do conhecimento e para as estratégias de sobrevivência e avanço na JAMG, foi possível observar várias práticas já existentes, em particular nas fases: compartilhamento do conhecimento tácito e nivelação de conceitos. As fases criação e justificação de conceitos e construção de protótipos não foram citadas nas entrevistas. A análise aponta para várias oportunidades de melhoria, que devem ser trabalhadas pela organização, na busca de sua sobrevivência e avanço.

Quanto ao primeiro capacitador para o conhecimento - "Instilar a Visão do Conhecimento" -, pode-se afirmar que é utilizado parcialmente na JAMG. Este item, portanto, constitui-se como um ponto de melhoria para que a JAMG torne explícita a importância de ter o conhecimento como seu patrimônio principal, ponto fundamental para sua sobrevivência.

O segundo capacitador - "Gerenciar as Conversas" - foi analisado sob dois pontos de vista. O dia a dia dos trabalhos na organização foi considerado, pela totalidade dos entrevistados, como sendo um ponto forte para a criação e compartilhamento de informações e conhecimentos. O mesmo não se dá em relação ao aproveitamento dos conhecimentos gerados. As respostas sugerem que os resultados dessa interação podem não estar sendo integralmente capturados em benefício do grupo e da organização, uma vez que alguns respondentes afirmam não estar habituados a registrá-los. Surge aí outra oportunidade de melhoria para a JAMG com a possibilidade de estabelecimento de rotinas para a captura e o registro do conhecimento gerado na equipe. Importante ressaltar que Von Krogh et al. (2001) consideram o capacitador "Gerenciar as Conversas" como o mais impactante para o avanço da organização, uma vez que exerce forte influência sobre as cinco fases da criação do conhecimento.

Quanto ao terceiro capacitador - "Mobilizar os ativistas" -, os entrevistados foram unânimes em afirmar o grande estímulo que recebem por parte da Gerente Geral para o seu autodesenvolvimento e capacitação, de forma que esta melhoria se reverta em benefícios para cada um, para o grupo e resulte na melhoria dos resultados da organização Alguns pontos de melhoria foram identificados, como fortalecer as competências dos líderes em relação a sistematizar melhor os conhecimentos trazidos para a interioridade da organização, em benefício de todos os seus colaboradores, com o consequente reflexo benéfico nos resultados da JAMG.

O quarto capacitador - "Criar o Contexto adequado" - revela aquele que parece ser o ponto mais forte da organização: a qualidade de seu ambiente interno, no qual os relacionamentos dos colaboradores aparentam seguir as orientações de Von Krogh et al. (2001, p.22) no sentido de que sejam "permeados pela solicitude e pelo humanismo".. Também neste capacitador foram identificados pontos de melhoria. Alguns dos respondentes tiveram dúvidas se este ambiente é produto de estratégias deliberadas ou fruto do direcionamento da Gerente Geral ou, ainda, resultado da interação natural dos colaboradores. É importante que a criação do contexto capacitante, o $b a$, seja fruto de uma estratégia deliberada, visando a melhoria na transferência do conhecimento, ponto fundamental para a sobrevivência da organização.

Quanto ao quinto capacitador - "Globalizar o Conhecimento Local" -, os respondentes concordam que, no nível interno da organização, de um modo geral, o nivelamento do conhecimento gerado é realizado, mas com deficiências. Como causas, reportam ruídos de comunicação bem como ausência de registro dos conhecimentos gerados na interação da equipe, para uso e proveito de todos os colaboradores. Este pode ser considerado outro ponto de melhoria para a organização. A "Globalização do conhecimento local" aparenta ser o ponto que necessita de maior atenção por parte da JAMG para ser superado, ressaltando-se que este é um fato já conhecido pela equipe e incluído no plano de ações da organização.

Sugere-se que a JAMG reflita sobre a oportunidade de incluir, no planejamento estratégico da organização, metas de transferência do conhecimento e melhoria contínua, visando a sobrevivência da organização e de criação do conhecimento e inovação, visando seu avanço, alinhando-o aos planos de ação organizacionais, conforme modelo proposto por Von Krogh et al. (2001). 


\section{REFERÊNCIAS}

BNDES (2001) Terceiro setor e desenvolvimento social. Recuperado em: 23 jul.2013, de: http://www.bndes.gov.br/SiteBNDES/export/sites/d efault/bndes_pt/Galerias/Arquivos/conhecimento/re lato/tsetor.pdf.

Choo, C. W. (2003) A organização do conhecimento Como as organizações usam a informação para criar significado, construir conhecimento e tomar decisões. São Paulo: Editora Senac São Paulo.

Collis, J., Hussey, R. (2005) Pesquisa em Administração. (2. ed.) Porto Alegre: Bookman.

Davenport, T. H., Prusak, L. (2003) Conhecimento empresarial: como as organizações gerenciam o seu capital intelectual. (13. ed.) Rio de Janeiro: Elsevier.

Gil, A. C. (2002) Como elaborar projetos de pesquisa. (4. ed.) São Paulo: Atlas.

Junior Achievement Brasil. (n.d.) Página inicial. Recuperado em: 23 jul.2013, de: http://www.juniorachievement.org.br/ja/index.php? option=com_content $\& \mathrm{id}=3507 \& \&$ task $=$ view $\&$ Item id=76\&menu_pai=73.

Junior Achievement de Minas Gerais. (n.d.) Página inicial. Recuperado em: 23 jul.2013, de: http://www.jamg.org.br/.

Junior Achievement EUA. (n.d.) Fact sheet. Recuperado em: 23 jul.2013, de: https://www.juniorachievement.org/web/jausa/fact-sheet.

Júnior, M. V. de C. (2013) A contribuição da aprendizagem organizacional e da gestão do conhecimento nas estratégias de sobrevivência e avanço dos negócios de uma empresa familiar de médio porte. Dissertação de Mestrado. Pedro Leopoldo.

Kuniyoshi, M.S. et al. (2013) Institucionalização do knowledge based view: um estudo das práticas gerenciais de gestão do conhecimento e suas contribuições para a competitividade das empresas do setor elétrico-eletrônico. Revista de Administração da Unimep, 11(2), Maio/Agosto.

Nonaka, I., Takeuchi, H. (1997) Criação de conhecimento na empresa. (13. ed.) Rio de Janeiro: Elsevier.
Portal Brasil. (2013) Economia e emprego. Notícias. Medidas impulsionam competitividade industrial brasileira. Recuperado em: 23 jul.2013, de: http://www.brasil.gov.br/noticias/arquivos/2013/04/ 10/medidas-impulsionam-competitividadeindustrial-brasileira.

Portal G1 (Globo). (2013) Brasil deve recuperar posto de $6^{\text {a }}$ maior economia em 2013, mostra FMI. Recuperado em: 23 jul.2013, de: http://g1.globo.com/economia/noticia/2013/04/brasi 1-deve-recuperar-posto-de-6-maior-economia-em2013-mostra-fmi.html.

Portal Uol (2013) Recuperado em: 2 junh.2014, de: http://mais.uol.com.br/view/1575mnadmj5c/podere-politica-jorge-gerdau-completo-56-min0402CC1A3570C4994326?types $=$ A\&.

Probst, G., Raub, S., Romhardt, K. (2002) Gestão do conhecimento: os elementos construtivos do sucesso. Porto Alegre: Bookman.

Sá, F.B. et al. (2013) Práticas de gestão do conhecimento: um estudo de organizações mineiras. Perspectivas em Gestão \& Conhecimento, João Pessoa, 3(1), 114-131, jan./jun.

Santos, A.E.M., Popadiuk, S. (2010) Gestão do conhecimento e a capacidade de competição. Revista Contemporânea de Economia e Gestão, 8(1) jan/jun (21-32).

Silva, M. (2013) Contribuições dos capacitadores do conhecimento e das estratégias de sobrevivência e avanço para o aumento da competitividade de uma empresa multinacional do setor alimentício. Dissertação de Mestrado. Pedro Leopoldo, Minas Gerais.

Stewart, T. A. (2002) A riqueza do conhecimento: o capital intelectual e a organização do século XXI. Rio de Janeiro: Campus.

Stewart, T. A. (1998) Capital intelectual: a nova vantagem competitiva das empresas. Rio de Janeiro: Campus.

Von Krogh, G., Ichijo, K., Nonaka, I. (2001) Facilitando a criação do conhecimento. Rio de Janeiro: Campus.

Yin, R. (2010) Estudo de caso: planejamento e métodos. (4. ed.) Porto Alegre: Bookman. 